\title{
Listening in: Spontaneous Teacher Talk on Playscapes
}

\author{
H. Kloos, C. Maltbie, R. Brown, V. Carr \\ University of Cincinnati, Cincinnati, USA \\ Email: heidi.kloos@uc.edu
}

How to cite this paper: Kloos, H., Maltbie, C., Brown, R., \& Carr, V. (2018). Listening in: Spontaneous Teacher Talk on Playscapes. Creative Education, 9, 426-441. https://doi.org/10.4236/ce.2018.93030

Received: January 12, 2018

Accepted: March 12, 2018

Published: March 15, 2018

Copyright (C) 2018 by authors and Scientific Research Publishing Inc. This work is licensed under the Creative Commons Attribution International License (CC BY 4.0).

http://creativecommons.org/licenses/by/4.0/

\begin{abstract}
Nature-based playgrounds-known as playscapes-offer numerous opportunities for young children to learn about nature. In the current study, we focus on teacher talk on playscapes, namely to capture the spontaneous utterances teachers offer when engaging with young children during playscape visits. Two different playscapes were contrasted, both of which featured loose parts, native plants, and running water. The difference in playscape was whether it featured ecosystems: While the rural playscape had a natural forest and a wetland, the urban playscape had a man-made stream and a garden. Ten preschool teachers participated with their classrooms. They wore microphones during a series of field trips to playscapes. No specific training was provided, and teachers were told to interact with children as they naturally would. Teacher audio was transcribed and coded to capture science-relevant, science-neutral, science-diverting, and supervisory teacher talk. Findings were analyzed by playscape and number of visits. Results show a strong effect of playscape type: Spontaneously occurring science-relevant utterances were about twice as likely on the rural as the urban playscape, even by the same teacher. In contrast, the amount of supervisory utterances differed only by teacher, not playscape. Finally, science-diverting utterances were very rare, underscoring the opportunities for science learning that lie in playscapes. Our findings have important implications for how to design professional-development tool to support teachers in the delivery of early environmental education.
\end{abstract}

\section{Keywords}

Early Science Education, Environmental Education, Play, Preschool

\section{Introduction}

Playscapes are playgrounds designed to resemble nature (Chatterton \& Hol- 
lands, 2002; Keeler, 2008). Rather than man-made playground equipment, they feature native plants, rolling hills, trees, logs, etc. While the specific details of playscapes differ, their design shares the explicit intent to expose children to nature in a safe and playful manner (Luken, Carr, \& Brown, 2011). This might include natural ecosystems (e.g., forests, swamps), or it might limit itself to gardens and man-made creeks (Fjortoft \& Sageie, 2000; Herrington \& Studtmann, 1998). There are several benefits attributed to the use of playscapes, including increased gross motor skills, increased attention span, decreased bullying, increased self-regulatory skills, and increased social skills (Carr \& Luken, 2014; Kochanowski \& Carr, 2014). In the current paper, we focus on how playscapes affect teachers and their spontaneous interaction with preschoolers. Our specific interest was on teacher talk relevant to science learning.

Over the last decade, science education has become a stable feature of the preschool curriculum. For example, in 2015, all state standards explicitly listed science at the preschool level, and $84 \%$ of them listed "life science" specifically. Related topics include naming and classifying plants and animals (31 states), identifying and describing characteristics of living things (26 states), identifying types of weather (23 states), demonstrating respect for preserving the environment (21 states), understanding what living things need to survive and grow (17 states), identifying seasons and seasonal changes (14 states), observing the sun's place in the sky during the day (14 states), describing relationships between animals, plants, and the environment in ecosystems (12 states), and distinguishing living from non-living things (10 states). It is likely that the number of topics will only increase (Kloos, Waltzer, Maltbie, Brown, \& Carr, 2018).

Yet, despite the push for early science education, there is no explicit curriculum, assessments, or milestones that could constrain the list of topics or when they should be introduced. While literacy skills and math skills have been mapped out carefully, down to proper assessments and benchmarking, early science education depends on the dedication of teachers to gather the necessary resources for lesson plans, science-relevant activities, and ways to measure children's progress. Similarly, while research on early science education is a rapidly growing field, it is still rather unorganized, driven by pedagogical innovations rather than by theoretical advances of the building blocks of early science learning (cf. Kloos, Baker, Luken, Brown, Pfeiffer, \& Carr, 2012).

Playscapes are yet another innovation that could promote early science learning-with unique advantages for theory building. Playscapes have the potential to impact development more broadly, including motor development, emotional development, and social development (Carr, Brown, Schlembach, \& Kochanowski, 2017). Within the domain of science, it offers multiple opportunities for learning, namely in the area of life science, earth and space science, and physical science. It even touches into other cognitive and academic domains, including math, spatial reasoning, map reading, tool use, and engineering, namely when building structures from natural materials. Given such broadness, research on 
playscapes allows for theory building about children's early learning in structured settings.

Teacher talk is likely to be quite crucial in affecting science learning. Typically, it might involve a triadic discourse in which the teacher poses a question, the student answers, and the teacher then provides either an evaluation or other feedback (e.g., Initiation-Response-Evaluation; Initiation-Response-Feedback; Mehan, 1979; Mortimer \& Scott, 2003; Scott, Mortimer, \& Aguiar, 2006). Seah and Yore (2017) found that 4th grade teachers' science talk served the purposes of labeling, explaining, differentiating, selecting, and constructing. Generally, this type of discourse is viewed as more authoritative and less engaging for students. In contrast, dialogic discourse, in which students discuss their ideas and raise questions, is viewed as facilitating the construction of meaning and understanding.

Field trips to more informal science learning environments may afford different types of teacher talk in comparison to classroom contexts. For example, DeWitt and Hohenstein (2010) studied interactions between teachers and students in primary and secondary grades during classroom lessons and during a field trip to a science museum. They found that discourse during classroom lessons was more triadic than in the museum. In both settings, teachers predominantly asked questions that were closed-ended, task-related, procedural, and requiring only brief factual answers. However, the museum setting did lead some teachers to ask questions that invited more active participation. Building on these insights, we investigated the spontaneous teacher talk of preschool teachers visiting playscapes with their classroom.

\section{Overview of the Current Study}

In order to better understand teachers' spontaneous interactions on playscapes, several field trips were organized to local playscapes. There was a total of nine visits, six to a rural playscape located at a nature reserve, and three to an urban playscape located on a university campus. Both playscapes feature loose parts (e.g., rocks, logs), native plants, and running water. However, only the rural playscape has naturally grown ecosystems (e.g., forest, wetland). Each teacher wore a microphone during his or her visits. Audio was transcribed and coded to capture science-relevant, science-neutral, science-diverting, and supervisory teacher talk. Results were then analyzed to determine the relative impact of the type of playscapes (rural vs. urban) and the effect repeated visits had to teacher talk over time (one, two, or three visits).

\section{Method}

\subsection{Participants}

Two local preschool centers were recruited to participate in field trips to playscapes. Across the two centers, there were seven classrooms and thirteen teachers ( 2 male teachers and 11 female teachers). Teachers differed in their teaching 
experience (ranging from new hires to over ten-year veteran teachers), and they differed in their education (from a Child Development Associate (CDA) Credential to a Masters of Education). All but one teacher identified himself or herself as Caucasian. Both preschool centers accepted head start and tuition paying children and they received high-quality state rating for early care and education programs.

\subsection{Playscapes}

Two playscapes were visited for the current study, one located in the rural area of a nature preserve, and one located in the urban area of a university campus. The rural playscape is a 1.6 acre, fenced area within the 1000-acre preserve. It contains a natural forest, open prairies, a recirculating stream, a wetland habitat, small caves, several rock formations, a bridge, a tepee, sand and gravel pits, a bird blind, and circular paths weaving around and through the space (see Figure 1). This playscape also has shrubs and vegetation, and there are two semi-constructed $\log$ forts in the forest area. Upon entering, there is a shaded terrace with wooden benches and a large child-friendly map of the space. Visitors can interact with the features as desired.

The urban playscape is a 0.23 acre, fenced area on an urban university campus. It is heavily planted with indigenous species and contains a non-recirculating stream, a treehouse, a log fort, sand and gravel pits, a garden, a bird blind, a rolling hill, maps, natural loose parts, and circuitous paths (see Figure 2). Its entrance has a gathering space for children and teachers, as well as a curriculum headquarters, which is a shed-type structure that contains first aid materials and manufactured loose parts for play. This playscape was created for use by the university preschool, but it also open to the public (except the curriculum headquarters).

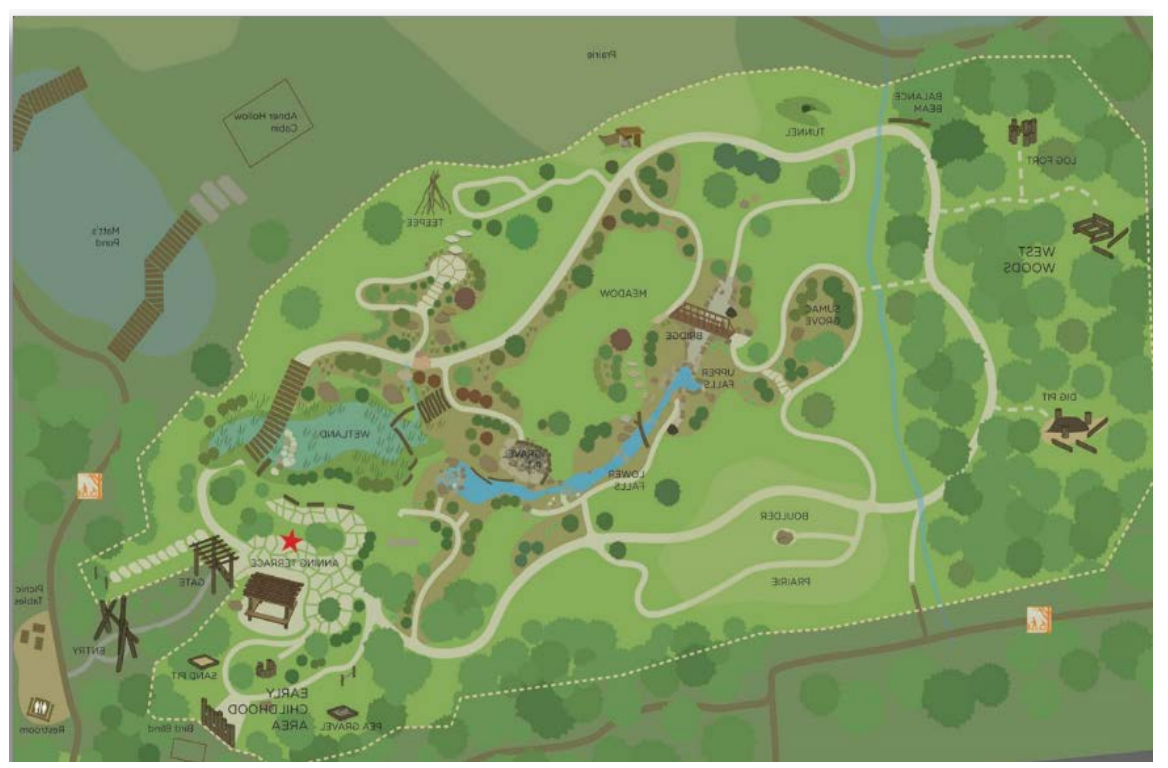

Figure 1. Schematic of Rural Playscape. 


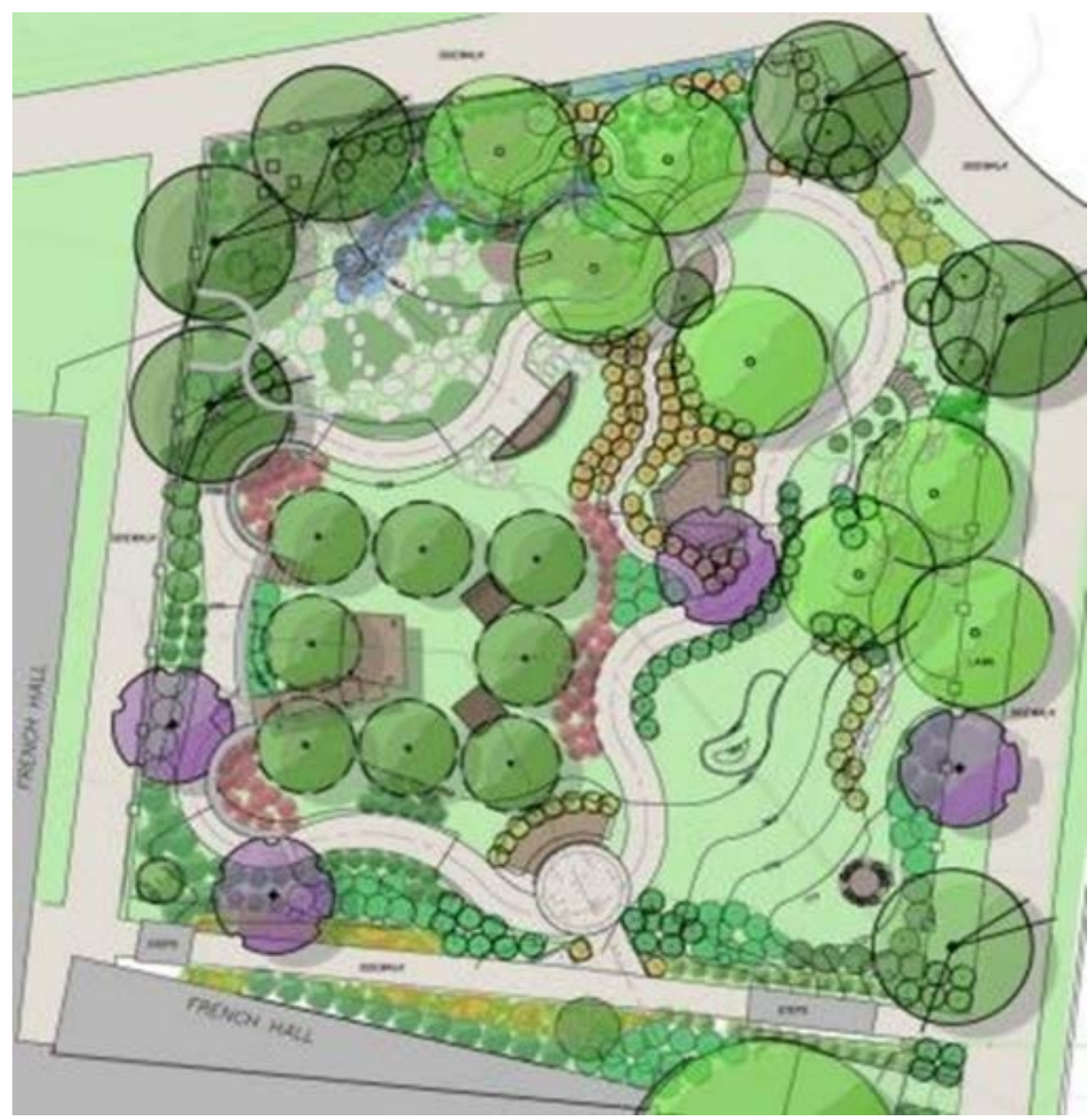

Figure 2. Schematic of the Urban Playscape.

\subsection{Procedure}

Between the months of March and May, seven preschools classrooms visited one or both playscapes. Upon arrival, participating teachers were outfitted with a lavalier microphone attached to a digital voice recorder. Their voices were recorded throughout the entire playscape visit, approximately one hour. They were instructed to interact with the children as they naturally would. All audio was transcribed by research assistants who were blind to the specific goals of the study. Twenty-five audio files could be coded (stemming from ten teachers).

\subsection{Data Coding}

Teacher audio was divided into chunks of utterances. Depending on the content, chunks could vary in length from a few words to whole sentences. The relevant aspect was for a chunk to convey only one concrete idea. Codes were developed to capture the extent to which teacher talk was relevant to playscape-relevant science. For this purpose, we settled on a definition of science that was mirrored in state standards of early science education (Kloos et al., 2018). Specifically, utterances could be science-relevant, science-diverting, supervisory, or scienceneural.

Utterances were coded as science-relevant when the teacher labelled living 
things (e.g., geese, trees, flowers), pointed out a feature that could be observed in nature (e.g., color, sound, shape), or offered probing questions pertinent to the surrounding (e.g., "where does this come from?"). We also coded utterances as science-relevant if they conveyed or prompted a comparison (e.g., "more"), if they referred to way finding and map use (e.g., "where are we going"), or if they mentioned number concepts (e.g., "let's count the rocks"). In contrast, mentioning an object or living thing as part of a make-believe game or dramatic play was not considered science-relevant.

Some utterances could be construed as running counter to main-stream science education. Examples are to say something that is factually wrong (e.g., "mices", "you sound like a dinosaur"), to attribute an observation to magical forces (e.g., "there is magic in the grass"), or to ask children to look for something that could not be found at the visit (e.g., dinosaurs, wolfs, pandas). While these utterances include naming living things and prompting children to engaging in observations, we nevertheless deemed these types of utterances as science-diverting in the context of playscapes. This was because children appeared to take the utterances seriously, outside of make-believe activities or dramatic play. We refer to these utterances as science-diverting.

A third category of utterances pertains to supervision. This includes expressing a worry about children getting wet, dirty, or hurt. It also includes stating a rule, scolding children who misbehave, or praising children who show good behavior. Other examples of supervision utterances are to soothe children in distress, to take care of children's needs (e.g., help them find wipes to clean their hands), and to complete organizational tasks (e.g., discuss lunch options). All other utterances were deemed science-neutral. This includes make-believe conversation and dramatic play ("are you making dinner?"). It also includes helping children out in various non-emergency activities, such as holding onto a bouquet of flowers so children could climb on a log, hand children loose parts to build a structure, or look for something children were hoping to find. Finally, it included any conversation that was unrelated to the playscapes (e.g., discussing an upcoming birthday).

Note that teacher utterances were coded in the same way, whether speech was directed towards children or adults (e.g., other teachers). This is because the audio made it impossible to determine the listeners conclusively. For example, in some cases, even though the teacher talked to another adult, children could be heard nearby, potentially listening in and being affected by the conversation among adults. At the same time, we did not code any teacher talk that took place prior to children entering the playscape (e.g., when the teacher helped children get ready) or when the teacher left the playscape (e.g., to take a child to the bathroom).

\section{Results}

Across teachers and visits, 25 audio files were usable. The average number of 
utterances across tapes was 45.2 (Median $=48 ; S D=16.9$ ) and the minimum number was 14 . Two teachers had only one audio file, while two teachers had four audio files. Each teacher had one audio file from a visit to the rural playscape, and four teachers had audio files from a visit to the urban playscape. Figure 3 shows how each of the audio files maps unto teacher, playscape, and visit. Specifically, teachers are denoted by capital letters (A-J); individual visits are denoted by vertical lines; and the type of playscape is denoted by whether the vertical line is solid (urban playscape) or dashed (rural playscape).

Figure 3 shows the proportion of science-relevant, science-neutral, and supervisory utterances. Note that science-diverting utterances are not included. This is because this type of utterances occurred very rarely (less than $2 \%$ of all coded utterances). Three teachers made no science-diverting comments at all, another three teachers made only one science-diverting comment across all their visits, and another two teachers made no more than two science-diverting comments per visit. Only one teacher had more than two comments of this type (e.g., when prompting children to go find dinosaurs). Even so, the proportion of science-diverting utterances for this teacher was only $7 \%$ of utterances across visits.

\subsection{General Observations}

Across teachers and visits, there were at least 300 utterances per type (sciencerelevant, science-neutral, supervisory), providing sufficient data to analyze their frequency. While there were more supervisory $(M=36 \%)$ and science-neutral

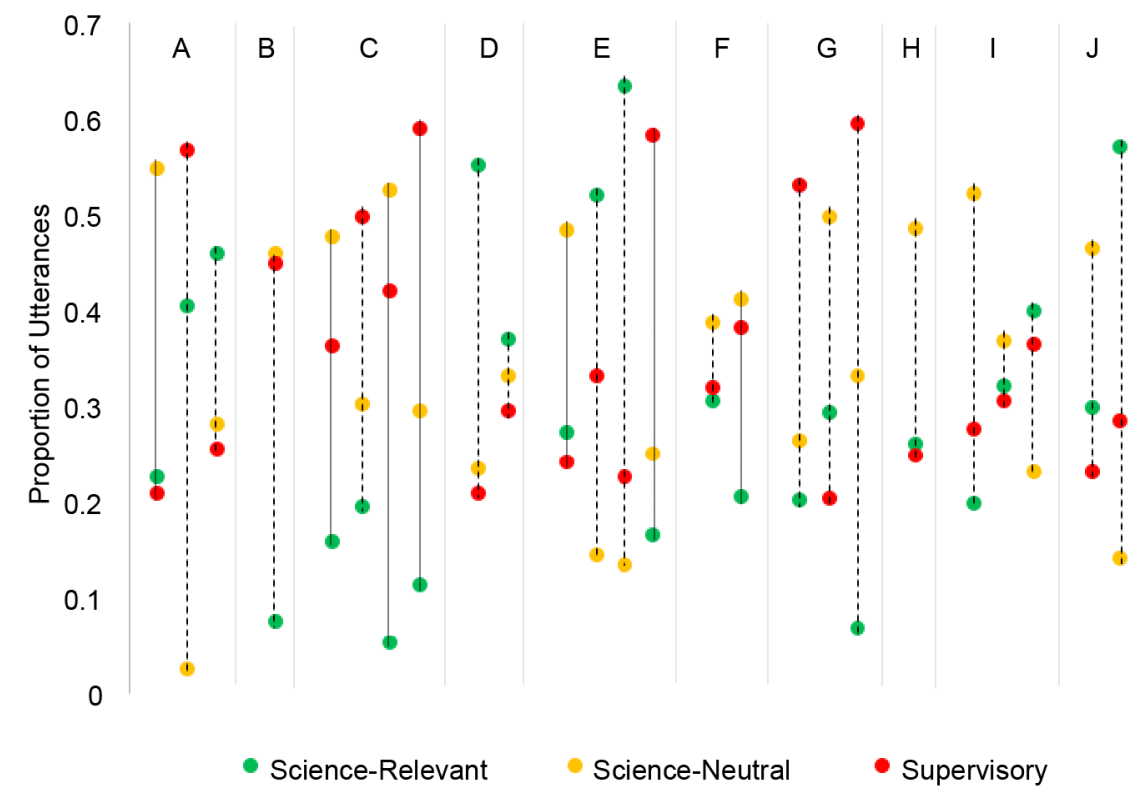

Figure 3. Proportion of types of utterances per teacher and visit (science-relevant utterances: green dots; science-neutral utterances: yellow dots; supervisory utterances: red dots). A-J refer to different teachers, each letter being associated with a certain number of vertical lines. Each vertical line represents a visit. Specifically, solid lines mark a visit to the urban playscape, and dashed lines mark visits to the rural playscape. 
( $M=35 \%)$ than science-relevant utterances $(M=29 \%)$, this difference was not significant (e.g., paired-sample $t$-test comparing the proportion of science-relevant to supervisory utterances: $t(24)=1.5, p>.21$ ).

There was high variability in the proportion of different types of utterances. For example, the proportion of science-relevant utterances (green dots in Figure 3 ) ranges from $5 \%$ to $65 \%$. For science-neutral and supervisory utterances (yellow and red dots in Figure 3), the range of proportions was somewhat smaller ${ }$ Range $_{\text {Science-neutral }}=3 \%-53 \%$; Range $e_{\text {Supervisory }}=20 \%-60 \%$; respectively). Even so, obvious patterns were rare. Variability of distributions appeared high, even from one visit to the next of the same teacher. In what follows, we discuss whether the type of playscape and familiarity can account for some of the variability.

\subsection{Type of Teacher Talk by Playscape}

To determine whether the rural playscape elicits a different kind of teacher talk than the urban playscape, we first looked at the proportion of types of utterances separately by playscapes. We included all teachers, even if they visited only one playscape, yielding 18 audio files from the rural playscape and 7 audio files from the urban playscape. Figure 4 shows the results.

A mixed-design ANOVA was carried out, with type of playscape (rural vs. urban) as the between-group factor, and type of utterance as the within-group factor. Results show a significant effect of utterance, $F(2,22)=5.2, p<0.03$, and a significant playscape by utterance interaction, $F(2,22)=3.2, p<0.05$. Specifically, the rural playscape elicited more science-relevant comments $\left(M_{\text {rural }}=.34 \%\right)$ than the urban playscape $\left(M_{\text {urban }}=.17 \%\right), t(23)=5.24, p<.02$. The difference in proportion of science-neutral utterances by playscape reached marginal significance, $t(23)=1.9, p<.08$, but not the difference in proportion of supervisory utterances, $t>.34$.

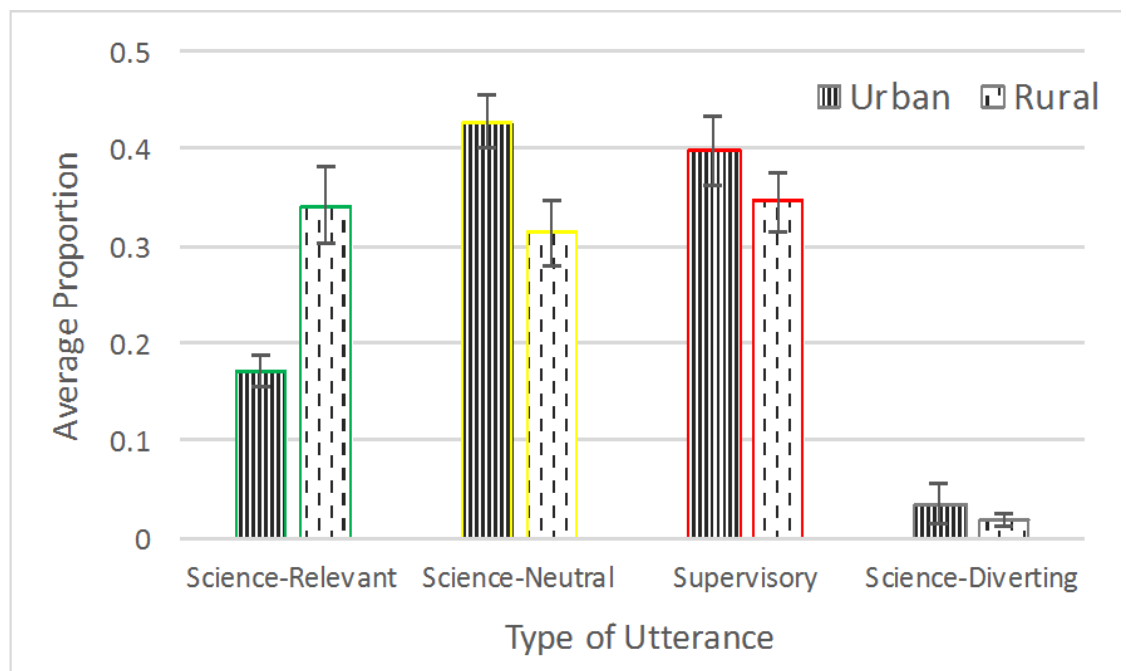

Figure 4. Average proportion of utterances across teachers and visits, separated by type of playscape (urban vs. rural) and type of utterance (science-relevant, science-neutral, supervisory, and science-diverting). Error bars show standard errors of the mean. 
What do teachers say on the rural playscape? A large number of science-relevant utterances were about the flowers on the playscape (e.g., their color, shape, or smell). In fact, all teachers mentioned flowers at least once. Many other utterances referred to the animals that children saw or heard (e.g., slugs, frogs, worms, birds). Utterances ranged from naming the animals (e.g., "look at all the worms [under the log]"), offering facts about them (e.g., "worms like to live"), explaining how to handle them (e.g., "don't put the worm in your pocket"), and asking questions about them (e.g., "what do worms do?", "what helps flowers grow?"). Other utterances were about trees (e.g., "the tree is alive"), rocks (e.g., "can you get fire out of these rocks?"), and sticks (e.g., "look at how the stick made a line").

Science-relevant talk also pertained to the map and numbers. For example, several teachers prompted children to count sticks or other loose parts. Some teachers invited children to check out the map, and one teacher explained "the star [on the map] is where we are". Finally, many teachers engaged children in the scientific process. For example, sometimes teachers offered explicit comparison, or they provided prompts for children to generate them. There were also some "why" questions (e.g., "why do you think the sticks don't bend"; "why do you think this [stick] is not heavy?"; "why is it so bright today?"; "why does the leaf have a hole?"). However, teachers offered very little spontaneous follow-up to children's answers.

It is important to note that some areas of the playscape elicited far less science-relevant talk than others. For example, while there were quite a few teacher utterances at the water feature of the playscape, the majority of them were supervisory in nature (e.g., to help children stay safe). Similarly, teacher talk in the context of interacting with loose parts included many science-neutral utterances (e.g., dramatic play using sticks and rocks for make-believe dinner). While there were some science-relevant utterances (e.g., "this is a heavy log"), the most reliable science-relevant utterances were made in the context of plants and animals. This could explain the difference in teacher talk that we observed between the rural and the urban playscape: Even though there were plants and animals on both playscapes, there were far more of them on the rural playscape.

In sum, it appears that the number of science-relevant comments is strongly affected by specific events that take place at the playscape. When children found bugs, frogs, and other living things, the amount of science-relevant teacher talk increased sharply. If, on the other hand, such an incidence did not happen during a particular visit, teachers commented less on science related events.

\subsection{Change of Teacher Talk with Time}

How did utterances change over time, as teachers gained more experience with a playscape? To answer this question, we looked at data from the rural playscape only: All teachers visited the rural playscape at least once, seven teachers returned for a second visit, and two teachers returned for a third visit to the rural 
playscape. Given that there was no obvious effect of timing in amount of science-neutral and supervisory utterances, we combined these two types of utterances. The goal then was to compare the proportion of science-relevant utterances against the proportion of other utterances from the first to the second visit of the rural playscape. Figure 5 shows the findings.

Given unequal $N$ per cell, we carried out a mixed-design ANOVA (visit is the between-group factor ${ }^{1}$ and utterance is the within-group factor). Results show a significant interaction between type of utterances (science-relevant vs. neutral/supervisory) and visit (Visit 1 vs. Visit 2 ), $F(1,13)=3.21, p<0.04$. While the number of science-relevant utterances increased over time (from an average of $31 \%$ to $41 \%$ ), the number of science-neutral and supervisory utterances decreased (from an average of $69 \%$ to $59 \%$ ).

To determine whether this trend holds up for teachers individually, we carried out a case-study design with two teachers who visited the rural playscape three times in a row (Teachers G and I). Transcripts contained about the same number of utterances (160 and 169, respectively), and their visits happened at the same time.

For Teacher G, over half of the utterances during the first visit were supervisory in nature (53\%). For example, children were reminded to 'be careful', they were helped (e.g., to climb a structure, to break up a fight), and they were offered wipes and other essentials. About half of the remaining utterances were science-neutral (27\%). They referred to holding flower bouquets, comments on children being nice, and helping children build and decorate a structure. There were also comments related to various make-believe activities, sometimes

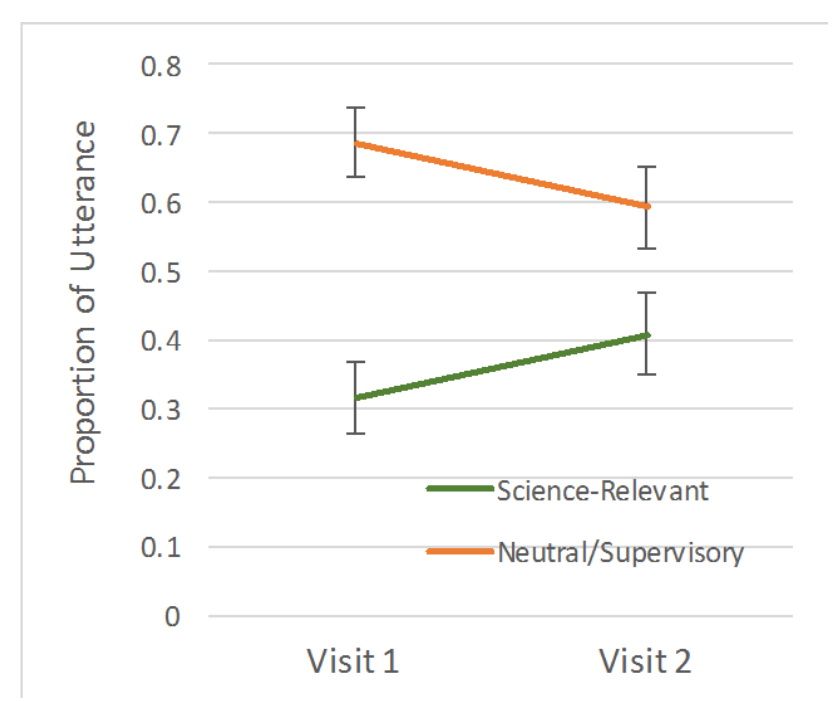

Figure 5. Average proportion of utterances of teachers visiting the rural playscape. Data for science-neutral and supervisory teacher talk were combined. Error bars show standard errors of the mean.

\footnotetext{
${ }^{1}$ The pattern of results remains the same with a repeated-measure design that includes teachers who completed both visits.
} 
initiated by the children (e.g., a child pretended to be cat) and other times initiated by the teacher (e.g., inviting children to pretend to be on Madagascar). In terms of science-relevant teacher talk (20\%), utterances were questions about what children were doing, what they found, where they have been, and what they saw.

By the second visit, the content of utterances of Teacher $G$ had changed noticeably. Supervisory comments decreased to a mere $20 \%$, focusing mostly on imparting rules (e.g., to stay away from an area) and helping children (e.g., with clothing, holding flowers, or being distressed by spiders). The majority of utterances were now science-neutral (50\%). For example, there was a conversation about whom to pick flowers for and where to store flower bouquets. There were also conversations about clothing, school routines, and family members. In terms of science-relevant and science-diverting utterances, the amount stayed largely the same: The teacher offered probing questions (e.g., "what is the color of pollen"; "where do squirrels live") and commented on flowers and rocks they observed (e.g., "flowers are just now blooming").

The distribution of science-relevant and science-neutral utterances for Teacher G, vis-à-vis the teacher's supervisory utterances, changed yet again by the third visit. Supervisory utterances became again most prevalent (60\%), with a strong emphasis on reminding children not to "horse around", not to "loose shoes", and to "be careful". In contrast, science-relevant utterances decreased sharply to only $7 \%$. The remaining utterances were science-neutral (33\%), including, for example, general descriptions of the playscape (e.g., that the water is turned on) and make-believe prompts (e.g., inviting children to catch fish for dinner in the stream). Thus, the increased exposure to the playscape did not result in a trajectory of increased science-relevant teacher talk for this teacher.

A rather different teacher-talk profile emerged for Teacher I. During the first visit, science-neutral utterances were the most common (52\%). They largely pertained to helping children build a structure with sticks (e.g., "where do you want the stick to go?"), and they pertained to comments on children's behavior with logs (e.g., "you could sit on the log"). There were also some comments related to make-believe (e.g., "we could pretend it's a cake") and to events outside of the playscape (e.g., upcoming birthdays). Science-relevant comments and supervisory comments occurred at an about equal rate. They pertained, for example, to counting or describing the logs (e.g., "this one is thinner"; "the small one is more wobbly"), and they pertained to helping children in distress.

During the second and third visit, the amount of science-neutral comments of Teacher I decreased (to $37 \%$ and $23 \%$, respectively), while the amount of science-relevant and supervisory comments increased (from approximately $30 \%$ to approximately $40 \%$ each). Science-neutral comments were about events outside the playscape (e.g., an upcoming birthday), descriptions of children's activities (e.g., "you are on the move"), and make-believe conversations (e.g., "let's visit her house"). Science-relevant comments were about flowers (e.g., "they bloomed 
overnight"), about the map and way-finding (e.g., "where are we on the map?"), and about animals that children found on the playscape (e.g., worm on the second visit; frog on the third visit). Supervisory comments continued to pertain to helping children (e.g., to dry off, to clean off the mud, to walk without slipping).

Taken together, there are striking differences in utterances of Teachers G and I, even though the total number of utterances is about the same, occurring during the same time frame (i.e., on the same visit). For one teacher, the types of utterances changed in the direction of less science-neutral, in favor of more science-relevant talk over time. In contrast, the changes were in the opposite direction for the other teacher: Science-relevant talk decreased over time, in favor of science-neutral and supervisory talk. This latter teacher (G) made at least one science-diverting utterance per visit and offered far more supervisory utterances than Teacher I (i.e., 77 vs. 49 across visits).

Individual differences in teacher talk on the rural playscape were typical. For example, Teacher A went from majority supervisory utterances to majority science-relevant utterances. In contrast, Teacher J went from majority scienceneutral utterances to majority science-relevant utterances. In yet another example, Teacher D started off with a majority of science-relevant utterances and then switched to having about the same number of relevant, neutral, and supervisory utterances. Interestingly, individual differences were far less prominent on the urban playscape. For example, both teachers who visited the urban playscape twice changed only in science-neutral and supervisory utterances. The amount of science-relevant utterances remains stable throughout.

\section{Discussion}

Our goal was to shed light on what teachers say when they visit playscapes with their preschool classrooms. We were specifically interested in teacher talk that occurs spontaneously, without teachers being given any specific training about playscapes. Our method was a mixed-methods approach to reveal the extent to which teachers' utterances are science-relevant. The science-relevant utterance was contrasted with science-neutral utterances, as well as supervisory utterances and utterances that ran counter to mainstream science (i.e., science-diverting utterances). To get at the effect of context, teacher talk at two types of playscapes was recorded: a playscape located in a rural area of a nature preserve, and a playscape located in an urban setting. Teachers visited these playscapes during the spring.

Several results are of interest. Most striking are the inter-individual and intra-individual differences among teachers from one visit to the next. For example, while some teachers richly supplemented children's experience of nature with hands-on activities, engaging explanations, and targeted questions, other teachers did not. In some cases, patterns of teacher talk were specific to the individual teacher, remaining stable from one visit to the next. Other times, the context played an important role in the type of talk that teachers engaged in. For 
example, while some teachers offered more science-relevant utterances than others, the presence of animals or plants greatly increased the amount of science-relevant utterances.

Our findings offer further support for the promise of playscapes. This is because all teachers uttered at least some science-relevant phrases on each of the playscapes. They did so without explicit instructions and without knowing about our focus on science learning. Most likely, teachers' own science training is at the level of the average community, which makes it even more impressive that they offered science-relevant comments reliably. Interestingly, the content of teacher's science-relevant utterances was multifaceted: It included labels, facts, questions, and prompts, whether in the domain of life science (e.g., plants, animals), physical science (e.g., heaviness of logs), and earth and space science (e.g., weather, shadows).

Our findings also point to ways of improving teacher talk on playscapes. One such opportunity lies in enriching playscapes with science-relevant content and opportunities for children to explore this content. Our data shows that teachers reliably offer science-relevant utterances when children are engaged in science explorations themselves. Thus, the more the surrounding is inviting to children's science-explorations, the more teachers are likely to chime in and become partners in the learning processes. One straight-forward way to do that on playscapes is to increase the number of natural habitats and ecosystems.

Even when extensive ecosystems are missing (e.g., in urban settings), there are ways to ensure reliable science-relevant teacher talk. This is via professional development that provides teachers with science-relevant information. Our findings show that the pallet of science-relevant teacher talk was narrow for some teachers. For these teachers, it was therefore difficult to engage in extended conversations about science-relevant topics, beyond an initial prompt or questions. For example, when a girl picked up a rock that was sparkling, the teacher reacted in science-relevant ways: S/he asked the girl about why the rock might be so sparkly on one side but not the other side. However, no follow-up was offered and the conversation ended after only one question. This finding is consistent with other research indicating that preschool teachers' use of extended discourse was infrequent (e.g., Dickinson, Darrow, \& Tinubu, 2008; Jacoby \& Lesaux, 2014). Professional development on content relevant to preschool science topics could help all teachers engage in more prolonged conversations. It might even help teachers avoid science-diverting comments. For example, Hojnoski, Polignano, and Columba (2016) found that training and instructional supports increased preschool teachers' mathematical talk.

Another opportunity for professional development lies in addressing issues of supervision. Across both playscapes, there were quite a few utterances geared towards helping or taking care of children, for example when the teacher perceived unsafe behavior, or when children were distressed. Some teachers managed to swiftly help children (e.g., "just rub your hands to get [the dirt] off"). But other 
teachers took much longer (e.g., "you can't wipe your hands on her shirt. You need [to find] wipes"). The amount of concerns expressed by teacher about staying safe, dry, or clean could distract teachers from science-based exploration with their students. Similarly, the apparent lack of established routines and rules required teachers to establish them ad-hoc and for each new context (e.g., about whether it is allowed to pick flower).

Finally, our audio footage highlights the large differences from one teacher to the next (in addition to the differences from one context to the next). For example, while one of the teacher's audio was largely small talk, another teacher managed to sustain in-depth nature-based conversations, for example about a fungus growing on logs. Teachers also differed in the amount of hands-on engagement they offered. While some teachers interacted with children from a distance, so to speak, other teachers were deeply involved in children's explorations. Likewise, teachers differed in the amount of science-neutral conversations they carried out. For example, while one teacher invited children to explore the shape, color, and smell of flowers, another teacher treated flowers as objects (e.g., as decoration in children's hair or to give as gift to teachers). For professional development to be successful, it might need to take into account this difference among teachers.

\section{Conclusion}

In conclusion, our analysis of teacher talk during preschool visits to local playscapes shows important strengths and opportunities when it comes to science education. Most striking perhaps was that nature-based events reliably elicited science-relevant teacher talk. In contrast, the proportion of science-diverting utterances was very small, despite a lack of explicit science training offered to preschool teacher. Opportunities lie in creating richly natural playscapes, especially playscapes that include animals and natural habitats. Once such playscapes are available, professional development could be minimal, allowing teachers to explore the environment together with the children.

\section{Ethical Approval}

All procedures performed in studies involving human participants were in accordance with the ethical standards of the institutional and/or national research committee and with the 1964 Helsinki declaration and its later amendments or comparable ethical standards.

\section{Informed Consent}

Informed consent was obtained from all individual participants included in the study.

\section{Acknowledgements}

Funding for this project was provided by the National Science Foundation (ISE 
1114674; AISL 1516191; PI: Carr). The authors would like to thank Mona Jenkins, Alan Wight, Leslie Kochanowski and Melissa Elchison for help with data collection. Talia Waltzer helped with reviewing the state standards for preschool science education. Olivia Duvall, Katie Cunningham, and members of the Children's Cognitive Research lab helped with transcribing the audio footage, as well as with the coding of the data.

\section{References}

Carr, V., Brown, R. D., Schlembach, S., \& Kochanowski, L. (2017). Nature by Design: Playscape Affordances Support the Use of Executive Function in Preschoolers. Children, Youth \& Environments, 27, 25-46. https://doi.org/10.7721/chilyoutenvi.27.2.0025

Carr, V., \& Luken, E. (2014). Playscapes: A Pedagogical Paradigm for Play and Learning. The International Journal of Play, 3, 69-83. https://doi.org/10.1080/21594937.2013.871965

Chatterton, P., \& Hollands, R. (2002). Theorising Urban Playscapes: Producing, Regulating and Consuming Youthful Nightlife City Spaces. Urban Studies, 39, 95-116. https://doi.org/10.1080/00420980220099096

Dickinson, D. K., Darrow, C. L., \& Tinubu, T. A. (2008). Patterns of Teacher-Child Conversations in Head Start Classrooms: Implications for an Empirically Grounded Approach to Professional Development. Early Education and Development, 19, 396-429. https://doi.org/10.1080/10409280802065403

DeWitt, J., \& Hohenstein, J. (2010). School Trips and Classroom Lessons: An Investigation into Teacher-Student Talk in Two Settings. Journal of Research in Science Teaching, 47, 454-473. https://doi.org/10.1002/tea.20346

Fjortoft, I., \& Sageie, J. (2000). The Natural Environment as a Playground for Children: Landscape Description and Analysis of a Natural Landscape. Landscape and Urban Planning, 48, 83-97. https://doi.org/10.1016/S0169-2046(00)00045-1

Herrington, S., \& Studtmann, K. (1998). Landscape Interventions: New Directions for the Design of Children's Outdoor Play Environments. Landscape and Urban Planning, 42, 191-205. https://doi.org/10.1016/S0169-2046(98)00087-5

Hojnoski, R., Polignano, J., \& Columba, H. L. (2016). Increasing Teacher Mathematical Talk during Shared Book Reading in the Preschool Classroom: A Pilot Study. Early Education and Development, 27, 676-691. https://doi.org/10.1080/10409289.2016.1102018

Jacoby, J. W., \& Lesaux, N. K. (2014). Support for Extended Discourse in Teacher Talk with Linguistically Diverse Preschoolers. Early Education and Development, 25, 1162-1179. https://doi.org/10.1080/10409289.2014.907695

Keeler, R. (2008). Natural Playscapes: Creating Outdoor Play Environments for the Soul. Lincoln, NE: Exchange Press.

Kloos, H., Waltzer, T., Maltbie, C., Brown, R., \& Carr, V. (2018). Playscapes, Nature, and Science for Preschoolers: A Time-Lag Analysis of Early Science Standards across the U.S. Poster to be presented at the 30th APS Annual Convention, San Francisco, CA.

Kloos, H., Baker, H., Luken, E., Brown, R. Pfeiffer, D., \& Carr, V. (2012). Preschoolers Learning Science: Myth or Reality? In H. Kloos, B. J. Morris, \& J. L. Amaral (Eds.), Current Topics in Children's Learning and Cognition (pp. 45-70). Rijeka, Croatia: Tech-Open Access Publisher. https://doi.org/10.5772/54119

Kochanowski, L., \& Carr, V. (2014). Nature Playscapes as Contexts for Fostering 
Self-Determination. Children, Youth and Environments, 24, 146-167. https://doi.org/10.7721/chilyoutenvi.24.2.0146

Luken, E., Carr, V., \& Brown, R. D. (2011). Playscapes: Designs for Play, Exploration, and Science Inquiry. Children, Youth and Environments, 21, 325-337.

Mehan, H. (1979). Learning lessons: Social organizations in the Classroom. Cambridge, MA: Harvard University Press. https://doi.org/10.4159/harvard.9780674420106

Mortimer, E. F., \& Scott, P. H. (2003). Meaning Making in Secondary Science Classrooms. Maidenhead: Open University Press.

Seah, L. H., \& Yore, L. D. (2017). The Role of Teachers' Science Talk in Revealing Language Demands within Diverse Elementary School Classrooms: A Study of Teaching Heat and Temperature in Singapore. International Journal of Science Education, 39, 135-157. https://doi.org/10.1080/09500693.2016.1270477

Scott, P. H., Mortimer, E. F., \& Aguiar, O. G. (2006). The Tension between Authoritative and Dialogic Discourse: A Fundamental Characteristic of Meaning Making Interactions in High School Science Lessons. Science Education, 90, 605-631.

https://doi.org/10.1002/sce.20131 